\title{
Anesthesia Management in a Patient Diagnosed with Kounis-Zavras Syndrome and Who has Brittle Asthma and Samter Triad
} Ozkan Onal' ${ }^{1 *}$ and Serdar Yılmaz ${ }^{2}$

${ }^{1}$ Department of Anesthesiology and Reanimation, Yuksek Ihtisas Education and Research Hospital, Turkey

${ }^{2}$ Department of Orthopedics and Traumatology, Numune Training and Educational Hospital, Turkey

\section{Introduction}

In Kounis-Zavras syndrome, vasospastic mediators released from mast cells as response to allergic stimulus lead to coronary vasospasm and result in acute coronary syndrome or angina pectoris [1]. In this case report, anesthesia management in a 35 year old female patient with Kounis-Zavras syndrome who had Samter triad and multiple drug allergy and had arrest previously due to drug allergy and hence who has implantable cardioverter defibrillator is presented.

\section{Case}

A 35 year old female patient who had multiple drug allergy, Samter triad and Brittle asthma was referred to emergency service with a picture of angioedema. Although Salbutamol $2.5 \mathrm{mg}$, metilprednisolon $40 \mathrm{mg}$ and feniramin $45.5 \mathrm{mg}$ were administered, clinical picture did not improve and patient was intubated with propofol induction and admitted to intensive care unit. It was learned that in the history of this patient's Brittle asthma and Samter syndrome were present as well as mitral failure and that in France, allergic reaction developed to drugs used both for mitral failure and drug allergy treatment and cardiac arrest developed. It was also learned that the patient was diagnosed with Brittle asthma, Samter period and Kounis-Zavras syndrome and implantable cardioverter defibrillator was placed. The list of the drugs which the patient is allergic to was obtained from the relatives of the patient. Blood gas oxygen saturation value was $60 \%$. Epinephrine, 0.5 $\mathrm{mg}$ s.c. metilprednisolon $80 \mathrm{mg}$ i.v., salbutamol nebul, lidocain $40 \mathrm{mg}$ i.v. and furosemid $40 \mathrm{mg}$, non-invasive positive pressure ventilation were administered. When the patient was cooperative and oriented, upon the improvement of respiratory parameters, the patient was extubated. After oral nutrition was initiated, anaphylaxis developed again due to sesame in the bread which she ate in breakfast and when there was no response to medical treatment, she was intubated again. During follow up in intensive care unit, she had anaphylactic picture again. As the duration of intubation was over 7 days. This picture recurred frequently, tracheotomy was opened. During intensive care monitorization, aseptic femur necrosis developed owing to high dose methylprednisolone administration, and operation was planned by orthopedics department. As she was known to be allergic to all kinds of local anesthetics, general anesthesia was planned and in operating room, electrocardiogram, oxygen saturation, invasive artery monitorization was carried out and against the probability of the development of anaphylaxis during operation, steroid, feniramin, and adrenalin were prepared beforehand. Since the patient was not allergic to egg and soy, $4 \mathrm{mg} / \mathrm{kg}$ propofol, fentanyl $2 \mathrm{mcg} / \mathrm{kg}$ i.v. was administered. Muscle relaxants were not administered as she was allergic to them. After induction, patient was connected to mechanical ventilation from tracheotomy canule and remifentanil and propofol infusion was initiated. No anesthetic gas was used and operation was completed without any complications.

\section{Discussion}

The incidental concurrence of chest pain and allergic reaction was defined by Kounis-Zavras in 1991. In these cases, clinical and laboratory findings caused by inflammatory mediators released against allergic condition support the presence of angina pectoris [2]. Currently, Kounis-Zavras syndrome has replaced the terms of allergic angina pectoris or allergic myocard infarction [1]. Two variants have been described. Type $I$ is an allergic insult resulting in coronary vasospasm giving rise to angina pectoris with or without myocardial infarction in the setting of normal coronary arteries. The type II variant occurs in a patient with underlying subclinical coronary atherosclerotic disease; the allergic insult is proposed to promote plaque rupture, leading to an acute coronary syndrome and subsequent degranulation of mast cells [3]. The mediators released include tryptase, chymase, histamine, platelet activating factor, cytokines, and others, apart from prostaglandin and leukotrine. Many of these compounds in susceptible patients stimulate coronary vasospasm in addition to platelet activation.

The management of these allergic angina pectoris syndromes involves the simultaneous treatment of acute coronary syndrome and allergic syndrome. Çevik et al. has recommended the treatment of anaphylactic or anaphylactoid reaction by means of epinephrine, corticosteroid, antihistaminic (both $\mathrm{H} 1$ and $\mathrm{H} 2$ blockers), fluid restriction and oxygen [4]. Our patient responded to this treatment.

Aspirin associated asthma was first defined by Widal et al. [5] and by Samter and Beers [6]. Samter triad term (asthma, aspirin hypersensitivity and nasal polyp) has become more popular. At present, it is regarded as a part of chronic eosinophilic rhinosinusitis syndrome AIA (Aspirin Induced Asthma). AIA, is anti-inflammatory condition affecting $5-10 \%$ of adults with asthma and etiology of which remains unknown [7]. Generally accepted hypothesis is that exposure to virus and genetic factors are influential. Samter-Beer triad first starts in the form of chronic sinusitis, subsequently nasal polyposis develops. Salicylate intolerance and asthma develop 1-5 years later [8]. Asthmatic patients with active bronchospasm presenting for emergency surgery should undergo a period of intensive treatment. Supplemental oxygen aerosolized beta2 agonists or intravenous glucocorticoid; owing to their bronchodilatator, anti-inflammatory and membrane stabilizing effects respectively, can dramatically improve lung function in a few hours. Preoperative sedation is important; particularly in the patients whose disease has an emotional component. Benzodiazepines are the drugs of choice for this purpose [9]. The most critical time for an asthmatic patient undergoing general anesthesia is during instrumentation of the airway. Pain, emotional stress or stimulation during light general anesthesia

${ }^{*}$ Corresponding author: Ozkan Onal, Department of Anesthesiology and Reanimation, Yuksek Ihtisas Education and Research Hospital, Turkey, E-mail drozkanonal@gmail.com

Received February 16, 2013; Accepted February 22, 2013; Published February 25,2013

Citation: Onal O, Yılmaz S (2013) Anesthesia Management in a Patient Diagnosed with Kounis-Zavras Syndrome and Who has Brittle Asthma and Samter Triad. J Clin Case Rep 3: 254. doi:10.4172/2165-7920.1000254

Copyright: ( 2013 Onal O, et al. This is an open-access article distributed under the terms of the Creative Commons Attribution License, which permits unrestricted use, distribution, and reproduction in any medium, provided the original author and source are credited. 
Citation: Onal O, Yılmaz S (2013) Anesthesia Management in a Patient Diagnosed with Kounis-Zavras Syndrome and Who has Brittle Asthma and Samter Triad. J Clin Case Rep 3: 254. doi:10.4172/2165-7920.1000254

Page 2 of 2

may promote bronchospasm. The cornerstone of general anesthesia is a smooth induction, avoiding drugs with histamine releasing characteristics such as thiopental, meperidine, morphine, atracurium, mivacurium and succinylcholine. Propofol and etomidate are appropriate agents for induction. Vecuronium bromide is the preferred muscle relaxant. Volatile anesthetics with their bronchodilating properties can be safely used for the maintenance of anesthesia. Intraoperative bronchospasm is usually presented as wheezing, increased peak inflation pressures, and lowered exhaled tidal volumes. The first approach must be deepening of the anesthesia. If wheezing does not settle, obstruction of the endotracheal tube, pulmonary edema or embolism, bronchospasm must be ruled out. Bronchospasm should be treated with adrenergic agonist, and steroids [9]. At the end of the surgery, reversal of nondepolarizing neuromuscular blocking agents with anticholinesterase does not elicit bronchoconstriction if anteceded by proper dose of an anticholinergic. Extubation must be carried out under deep general anesthesia so as to avoid bronchospasm [9]. When NSAID administered to patients with aspirin associated asthma, bronchopulmonary reactions, (bronchospasm, and larynx edema) or extrapulmonary findings similar to IgE mediated hypersensitivity reaction (rhynorrea, conjunctival infection, urticer like lesions) may appear. The sharp increase in cysteinyl leukotrienes that occurs with NSAID ingestion in AIA has been demonstrated to cause myocardial ischemia in patients with anatomically normal coronary arteries [10], probably on account of coronary vasospasm. Both AIA and allergic anginal syndromes are underdiagnosed to a large extent. In our patient, diagnosed Brittle asthma, Samter triad and Kounis-Zavras syndrome were concomitant in very rare occurrence.

\section{References}

1. Schwartz BG, Daulat S, Kuiper J (2011) The Kounis-Zavras syndrome with the Samter-Beer triad. Proc (Bayl Univ Med Cent) 24: 107-109.

2. Kounis NG, Zavras GM (1991) Histamine-induced coronary artery spasm: the concept of allergic angina. $\mathrm{Br} \mathrm{J}$ Clin Pract 45: 121-128.

3. Metzler B, Xu Q (1997) The role of mast cells in atherosclerosis. Int Arch Allergy Immunol 114: 10-14.

4. Cevik C, Nugent K, Shome GP, Kounis NG (2010) Treatment of Kounis syndrome. Int J Cardiol 143: 223-226.

5. Widal F, Abrami P, Lermoyez J (1993) Anaphylaxie et idiosyncrasie. 1992 [Anaphylaxis and idiosyncrasy. 1992]. Allergy Proc 14: 373-376.

6. Samter M, Beers RF Jr (1967) Concerning the nature of intolerance to aspirin J Allergy 40: 281-293.

7. Szczeklik A, Stevenson DD (2003) Aspirin-induced asthma: advances in pathogenesis, diagnosis, and management. J Allergy Clin Immunol 111: 913921.

8. Szczeklik A, Nizankowska E, Duplaga M (2000) Natural history of aspirin induced asthma. AIANE Investigators. European Network on Aspirin-Induced Asthma. Eur Respir J 16: 432-436.

9. Morgan E, Michail M, Murray M (2002) Anesthesia for patients with respiratory disease. In: Clinical Anesthesiology. (3rdedn), New York: The Mc Graw-Hill Com 512-516.

10. Szczeklik A, Nizankowska E, Mastalerz L, Bochenek G (2002) Myocardia ischemia possibly mediated by cysteinyl leukotrienes. J Allergy Clin Immunol 109: $572-573$. 